\title{
Prevalence and determinants of obesity among primary school children in Dar es Salaam, Tanzania
}

Alfa J Muhihi ${ }^{1,2^{*}}$, Rose N M Mpembeni ${ }^{3}$, Marina A Njelekela ${ }^{4,5}$, Amani Anaeli ${ }^{6}$, Omary Chillo ${ }^{4}$, Sulende Kubhoja ${ }^{7}$, Benjamin Lujani ${ }^{4}$, Mwanamkuu Maghembe $^{4}$ and Davis Ngarashi ${ }^{4}$

\begin{abstract}
Background: Childhood obesity has increased dramatically and has become a public health concern worldwide. Childhood obesity is likely to persist through adulthood and may lead to early onset of NCDs. However, there is paucity of data on obesity among primary school children in Tanzania. This study assessed the prevalence and determinants of obesity among primary school children in Dar es Salaam.

Methods: A cross sectional study was conducted among school age children in randomly selected schools in Dar es Salaam. Anthropometric and blood pressure measurements were taken using standard procedures. Body Mass Index (BMI) was calculated as weight in kilograms divided by the square of height in meters $\left(\mathrm{kg} / \mathrm{m}^{2}\right)$. Child obesity was defined as BMI at or above 95th percentile for age and sex. Socio-demographic characteristics of children were determined using a structured questionnaire. Logistic regression was used to determine association between independent variables with obesity among primary school children in Dar es Salaam.

Results: A total of 446 children were included in the analysis. The mean age of the participants was $11.1 \pm 2.0$ years and $53.1 \%$ were girls. The mean BMI, SBP and DBP were $16.6 \pm 4.0 \mathrm{~kg} / \mathrm{m}^{2}, 103.9 \pm 10.3 \mathrm{mmHg}$ and $65.6 \pm 8.2 \mathrm{mmHg}$ respectively. The overall prevalence of child obesity was $5.2 \%$ and was higher among girls (6.3\%) compared to boys (3.8\%). Obese children had significantly higher mean values for age $(\mathrm{p}=0.042)$, systolic and diastolic blood pressures (all $p<0.001)$. Most obese children were from households with fewer children $(p=0.019)$ and residing in urban areas $(p=0.002)$. Controlling for other variables, age above 10 years ( $A O R=3.3,95 \% C l=1.5-7.2)$, female sex $(A O R=2.6,95 \%$ $\mathrm{Cl}=1.4-4.9)$, urban residence ( $\mathrm{AOR}=2.5,95 \% \mathrm{Cl}=1.2-5.3)$ and having money to spend at school $(\mathrm{AOR}=2.6,95 \% \mathrm{Cl}=1.4-$ 4.8) were significantly associated with child obesity.
\end{abstract}

Conclusions: The prevalence of childhood obesity in this population was found to be low. However, children from urban schools and girls were proportionately more obese compared to their counterparts. Primary preventive measures for childhood obesity should start early in childhood and address socioeconomic factors of parents contributing to childhood obesity.

Keywords: Prevalence, Child obesity, Determinants, Urban, Children, Tanzania

\footnotetext{
* Correspondence: selukundo@gmail.com

${ }^{1}$ Africa Academy for Public Health, Dar es Salaam, Tanzania

${ }^{2}$ Ifakara Health Institute, Ifakara, Morogoro, Tanzania

Full list of author information is available at the end of the article
} 


\section{Background}

The increasing prevalence of childhood obesity has become a growing matter of public health concern worldwide. Obesity has increased from $4.2 \%$ in 1990 to $6.7 \%$ in 2010 worldwide and is expected to reach $9.1 \%$ in 2020 [1]. The risk is more for children in industrialized countries where the prevalence has increased more than twice in the past three decades [2]. In 2010, 43 million children were estimated to be obese worldwide, out of whom, 35 million (81.4\%) were from developing countries [1]. The estimated prevalence of childhood obesity in Africa in 2010 was $8.5 \%$ and is expected to reach $12.7 \%$ in 2020 [1]. North Africa is the region with highest prevalence of childhood obesity in Africa [3].

Few studies have been conducted on the prevalence of obesity among primary school children in Tanzania [4-6]. In a study conducted in Dodoma and Kinondoni, Mosha et al. showed that the prevalence of obesity among children aged 6-9 years was $5.6 \%$ and $6.3 \%$ respectively [5]. A similar low prevalence of child obesity (5.3\%) was also reported by Chillo et al. in a study conducted in Dar es Salaam and Morogoro regions [4].

Genetic and environmental factors have been documented as potential causes of obesity $[7,8]$. The rising prevalence of childhood obesity in developing countries is attributed to the growing urbanization, transition towards high caloric western diet of refined and fast foods and sedentary lifestyle $[9,10]$. Tanzania is not spared by the consequences of globalization, and profound societal changes have taken place especially in urban settings $[11,12]$. Leisure time activities are increasingly sedentary. Entertainments such as television, video and computer games are also widely and easily accessible. Hours spent on viewing television and computer usage is associated with increasing BMI among children [13]. Walking to and from school and morning joggings provided a potentially important opportunity for establishing daily physical activity among primary school children [14].

Literature from both, developed and developing countries have documented association between childhood obesity with many adverse health effects, ranging from hyperlipidemia, hypertension, respiratory disorders, glucose intolerance and type 2 diabetes mellitus, depression and low selfesteem to social discrimination [15-19]. All these adverse effects point to the necessity of preventing childhood obesity.

With the increasing body of evidence that childhood obesity often persist through adulthood [20-22] and higher possibility of lifestyle modification in children as opposed to adults, interventions aiming at modifying risk factors to prevent childhood obesity should be a top priority [23]. It is thus imperative to understand the magnitude and determinants of childhood obesity in order to develop effective preventive strategies. The present study assessed the prevalence and determinants of childhood obesity among primary school children in Dar es Salaam.

\section{Methods}

\section{Study design, site and population}

This cross-sectional study was conducted among primary school children aged 6-17 years from nine primary schools in three districts of Ilala, Kinondoni and Temeke in Dar es Salaam region. A sampling frame of all public and private schools in Dar es Salaam region was obtained from the district education authorities. Multistage cluster sampling was used to select schools to be involved in the study. Selection was made to ensure equal representation primary schools from both urban and rural settings of Dar es Salaam. Within each selected school one class (from class 1-7) was randomly selected and all children from the selected class were invited to participate into the study. Consent forms containing detailed information about the study were given to children to take to their parents. Signed consent forms were returned by the children on the scheduled day for data collection. Study questionnaires with both closed and openended questions were used to gather the required information from the participants.

\section{Anthropometric measurements}

Anthropometric measurements were conducted by trained research assistants early in the morning before classes began. Measurements were conducted in a dedicated room at each school with children wearing light clothes and with no shoes. Body weight was measured using a selfcalibrating precision digital scale (Omron, Japan). Height was measured to the nearest $0.1 \mathrm{~cm}$ by a fixed Shorr measuring board (Shorr Productions, Olner, MD). BMI was then calculated as weight in kilograms divided by the square of height in meters $\left(\mathrm{kg} / \mathrm{m}^{2}\right)$. All measurements were taken while observing standard precautions [24]. Child obesity was defined based on BMI percentiles for age and sex. Children with BMI at or above 95th percentile for age and sex were considered obese [25].

\section{Blood pressure measurements}

Blood pressure was measured using a standardized digital blood pressure measuring machine (Omron Digital HEM-907, Tokyo, Japan). Blood pressure readings were taken after the child had rested for at least 510 minutes. Blood pressure was measured on the left upper arm with the child in a seated position. Three readings were taken for each participant, and an average of the three readings was used during analysis.

\section{Sociodemographic information}

A structured questionnaire was used to collect sociodemographic information from the participating children. Important sociodemographic information was obtained 
Table 1 Socio-demographic characteristics of primary school children in Dar es Salaam, Tanzania 2011

\begin{tabular}{|c|c|c|c|c|c|c|c|}
\hline \multirow[t]{2}{*}{ Variable } & \multicolumn{2}{|l|}{ All $(\mathrm{N}=446)$} & \multicolumn{2}{|c|}{ Boys $(\mathrm{N}=209)$} & \multicolumn{2}{|c|}{ Girls $(\mathrm{N}=237)$} & \multirow[t]{2}{*}{ P-value } \\
\hline & Mean \pm SD & $(\mathrm{n}) \%$ & Mean \pm SD & $(n) \%$ & Mean \pm SD & $(n) \%$ & \\
\hline Age in years & $11.1 \pm 2.0$ & & $11.3 \pm 2.1$ & & $11.1 \pm 2.0$ & & 0.591 \\
\hline Place of residence & & & & & & & 0.294 \\
\hline Rural & & $197(44.2)$ & & $98(46.9)$ & & $99(41.8)$ & \\
\hline Urban & & $249(55.8)$ & & $111(53.1)$ & & $138(58.2)$ & \\
\hline Religion & & & & & & & 0.777 \\
\hline Christian & & $225(50.4)$ & & $107(51.2)$ & & $118(49.8)$ & \\
\hline Muslim & & $221(49.6)$ & & $102(48.8)$ & & $119(50.2)$ & \\
\hline Number of adults ( $\geq 18 \mathrm{yrs}$ ) & $6.2 \pm 2.2$ & & $6.3 \pm 2.3$ & & $6.2 \pm 2.0$ & & 0.949 \\
\hline Number of children (<18yrs) & $3.2 \pm 2.1$ & & $3.0 \pm 1.6$ & & $3.3 \pm 2.5$ & & 0.307 \\
\hline Education level of mother & & & & & & & 0.014 \\
\hline No formal & & $27(6.3)$ & & $11(5.5)$ & & $16(6.9)$ & \\
\hline Primary & & $144(33.3)$ & & $67(33.3)$ & & 77 (33.3) & \\
\hline Secondary & & $106(24.5)$ & & $46(22.9)$ & & $60(26.0)$ & \\
\hline College/University & & $68(15.8)$ & & 44 (21.9) & & $24(10.4)$ & \\
\hline No response & & $87(20.1)$ & & $33(16.4)$ & & $54(23.4)$ & \\
\hline Occupation of mother & & & & & & & 0.188 \\
\hline Housewife & & $86(20.2)$ & & $33(16.8)$ & & $53(23.1)$ & \\
\hline Business & & $183(43.0)$ & & $82(41.6)$ & & $101(44.1)$ & \\
\hline Farmer & & $59(13.8)$ & & $33(16.8)$ & & $26(11.4)$ & \\
\hline Government employee & & $39(9.2)$ & & $17(8.6)$ & & $22(9.6)$ & \\
\hline Other & & $59(13.8)$ & & $32(16.2)$ & & $27(11.8)$ & \\
\hline SBP & $103.9 \pm 10.3$ & & $103.4 \pm 10.4$ & & $104.3 \pm 10.2$ & & 0.111 \\
\hline DBP & $65.6 \pm 8.2$ & & $66.4 \pm 8.3$ & & $66.7 \pm 8.2$ & & 0.433 \\
\hline BMI & $16.6 \pm 4.0$ & & $16.1 \pm 4.04$ & & $17.0 \pm 4.0$ & & 0.002 \\
\hline
\end{tabular}

from parents/guardian during the interview. Education level of the parents/guardian was assessed and categorized as; no formal education (can neither read nor solve simple mathematics), primary education (attended school for up to 7 years), secondary education (attended school for 1214 years) and college/university education (attended university or attended school for 12 years and college training for 1 or more years. Parents'/guardians' main occupations were grouped as housewife, business, farmer and government employee.

\section{Statistical analysis}

Data analysis ranged from descriptive statistics (means, standard deviations and frequencies) describing the general characteristics to identification of statistically significant associations. Continuous variables were compared using t-test or Mann-Whitney $U$ test as appropriate while categorical variables were compared using chi-square $\left(X^{2}\right)$ test or fisher's exact test. Odds ratios (OR) and their 95\% confidence interval (CI) were estimated in univariate and multivariate analysis to measure the association of independent variables and child obesity. All statistical analyses were performed using Statistical Analysis Software (SAS 9.2, Institute Inc., North Carolina, USA) and values with $\mathrm{p}$-value $\leq 0.05$ were considered statistically significant.

\section{Ethical issues}

Ethical clearance was obtained from the Research Ethics Review Committee of Muhimbili University of Health and Allied Sciences. An informed consent to participate into the study was obtained from the parents/guardians of the selected children prior to the study. Confidentiality of information was adhered to by using unique identification numbers on the data collection tools instead of participant names. Questionnaires were stored in locked cabinets at MUHAS and were accessible to the researchers only.

\section{Results}

\section{Socio-demographic characteristics of the study} population

A total of 446 children from nine primary schools in Dar es Salaam were included into the study. The mean age of the 
Table 2 Prevalence of obesity among primary school children in Dar es Salaam, Tanzania 2011

\begin{tabular}{lrrrr}
\hline Characteristic & All (N=446) & Boys (209) & Girls (N=237) & P-value \\
\hline BMl category & & & & \\
Underweight & $65(14.6)$ & $36(17.2)$ & $29(12.2)$ & \\
Normal weight & $314(70.4)$ & $152(72.7)$ & $162(68.4)$ & 0.031 \\
Overweight & $44(9.8)$ & $13(6.3)$ & $31(13.1)$ & \\
Obese & $23(5.2)$ & $8(3.8)$ & $15(6.3)$ & \\
\hline
\end{tabular}

children was $11.1 \pm 2.0$ years $(11.3 \pm 2.1$ years for boys and $11.1 \pm 2.0$ years for girls). The mean BMI for girls $(17.0 \pm 4.0$ $\left.\mathrm{kg} / \mathrm{m}^{2}\right)$ was higher than that of boys $\left(16.1 \pm 4.0 \mathrm{~kg} / \mathrm{m}^{2}\right)$, and this difference was significant $(\mathrm{p}=0.002)$. Statistically significant gender difference was also observed for education level of the mother $(\mathrm{p}=0.014)$ (Table 1$)$.
Prevalence, distribution and characteristics of obese children Table 2 shows the prevalence of obesity in the population of primary school children in Dar es Salaam. The overall prevalence of child obesity was $5.2 \%$. Obesity was higher among girls (6.3\%) compared to boys (3.8\%). Similarly, the prevalence of overweight was higher among girls $(13.1 \%)$ compared to boys $(6.3 \%)$. The distribution of BMI categories among girls and boys was statistically significant $(\mathrm{p}=0.031)$.

Table 3 shows the distribution and characteristics of obese children. More girls were obese than boys with $6.3 \%$ and $3.8 \%$ respectively. The mean systolic and diastolic blood pressures were significantly higher among obese compared to non-obese children (all $\mathrm{p}<0.001$ ). The mean BMI was significantly higher among children from households with fewer number of children $(p=0.019)$. With regard to area of residence, children

Table 3 Distribution and characteristics of obese and non-obese primary school children in Dar es Salaam, Tanzania 2011

\begin{tabular}{|c|c|c|c|c|c|}
\hline \multirow[t]{2}{*}{ Variable } & \multicolumn{2}{|c|}{ Non-obese children } & \multicolumn{2}{|c|}{ Obese children } & \multirow[t]{2}{*}{ P-value } \\
\hline & Mean \pm SD & (n)\% & Mean \pm SD & (n)\% & \\
\hline Age in years & $11.2 \pm 2.1$ & & $12.0 \pm 1.2$ & & 0.042 \\
\hline \multicolumn{6}{|l|}{ Gender } \\
\hline Boys & & $201(96.2)$ & & $8(3.8)$ & 0.286 \\
\hline Girls & & $222(93.7)$ & & $15(6.3)$ & \\
\hline \multicolumn{6}{|l|}{ Place of residence } \\
\hline Rural & & $194(98.5)$ & & $3(1.5)$ & 0.002 \\
\hline Urban & & $229(92.0)$ & & $20(8.0)$ & \\
\hline \multicolumn{6}{|l|}{ Religion } \\
\hline Christian & & $211(93.8)$ & & $14(6.2)$ & 0.393 \\
\hline Muslim & & $212(95.9)$ & & $9(4.1)$ & \\
\hline Number of adults ( $\geq 18 \mathrm{yrs}$ ) & $6.3 \pm 2.2$ & & $5.7 \pm 1.4$ & & 0.379 \\
\hline Number of children (<18yrs) & $3.2 \pm 2.2$ & & $2.3 \pm 1.0$ & & 0.019 \\
\hline Education level of mother & & & & & 0.713 \\
\hline No formal & & $26(96.3)$ & & $1(3.7)$ & \\
\hline Primary & & $139(96.5)$ & & $5(3.5)$ & \\
\hline Secondary & & 99 (93.4) & & $7(6.6)$ & \\
\hline College/University & & $63(92.7)$ & & $5(7.3)$ & \\
\hline No response & & $82(94.3)$ & & $5(5.7)$ & \\
\hline Occupation of mother & & & & & 0.217 \\
\hline Housewife & & $78(90.7)$ & & $8(9.3)$ & \\
\hline Business & & $176(96.2)$ & & $7(3.8)$ & \\
\hline Farmer & & $58(98.3)$ & & $1(1.7)$ & \\
\hline Government employee & & $36(92.3)$ & & $3(7.7)$ & \\
\hline Other & & $56(94.9)$ & & $3(5.1)$ & \\
\hline SBP & $103.4 \pm 9.9$ & & $114.3 \pm 11.8$ & & $<0.001$ \\
\hline DBP & $66.0 \pm 7.9$ & & $75.8 \pm 9.7$ & & $<0.001$ \\
\hline
\end{tabular}


Table 4 Univariate analysis for predictors of obesity among primary school children in Dar es Salaam, Tanzania 2011

\begin{tabular}{|c|c|c|c|}
\hline Independent variables & Non-obese children N (\%) & Obese children N (\%) & COR $(95 \% \mathrm{Cl})$ \\
\hline \multicolumn{4}{|l|}{ Age (years) } \\
\hline 10 years or less & $136(98.5)$ & $2(1.5)$ & 1.0 \\
\hline Above 10 years & $287(93.2)$ & $21(6.8)$ & $2.9(1.4-5.9)^{\S}$ \\
\hline \multicolumn{4}{|l|}{ Gender } \\
\hline Boys & $201(96.2)$ & $8(3.8)$ & 1.0 \\
\hline Girls & $222(93.7)$ & $15(6.3)$ & $2.2(1.2-3.8)^{\S}$ \\
\hline \multicolumn{4}{|l|}{ Area of residence } \\
\hline Rural & $194(98.5)$ & $3(1.5)$ & 1.0 \\
\hline Urban & $229(92.0)$ & $20(8.0)$ & $2.9(1.6-5.3)^{\S}$ \\
\hline \multicolumn{4}{|l|}{ Education level of mother } \\
\hline No formal & $26(96.3)$ & $1(3.7)$ & 1.0 \\
\hline Primary & $139(96.5)$ & $5(3.5)$ & $0.3(0.1-1.1)$ \\
\hline Secondary & $99(93.4)$ & $7(6.6)$ & $0.8(0.3-2.3)$ \\
\hline College/University & $63(92.6)$ & $5(7.4)$ & $0.6(0.2-1.9)$ \\
\hline Declined response & $82(94.3)$ & $5(5.7)$ & $0.6(0.2-1.7)$ \\
\hline \multicolumn{4}{|l|}{ Occupation of mother } \\
\hline Housewife & $78(90.7)$ & $8(9.3)$ & 1.0 \\
\hline Business & $176(96.2)$ & $7(3.8)$ & $0.7(0.4-1.5)$ \\
\hline Farmer & $58(98.3)$ & $1(1.7)$ & $0.7(0.3-1.9)$ \\
\hline Government employee & $36(92.3)$ & $3(7.7)$ & $1.4(0.6-3.6)$ \\
\hline Other & $56(94.9)$ & $3(5.1)$ & $0.5(0.2-1.5)$ \\
\hline \multicolumn{4}{|c|}{ Money to spend at school/day } \\
\hline$\leq 500$ Tshs & $306(97.1)$ & $9(2.9)$ & 1.0 \\
\hline$>500$ Tshs & $117(89.3)$ & $14(10.7)$ & $2.2(1.3-3.8)^{\S}$ \\
\hline \multicolumn{4}{|l|}{ Religion } \\
\hline Christian & $211(93.8)$ & $14(6.2)$ & 1.0 \\
\hline Muslim & $212(95.9)$ & $9(4.1)$ & $1.2(0.7-2.1)$ \\
\hline \multicolumn{4}{|c|}{ Number of adults in the family } \\
\hline$\leq 4$ & $79(91.7)$ & $7(8.3)$ & 1.0 \\
\hline 5 to 7 & $249(94.3)$ & $15(5.7)$ & $0.8(0.4-1.5)$ \\
\hline$>7$ & $95(99.0)$ & $1(1.0)$ & $0.6(0.2-1.3)$ \\
\hline \multicolumn{4}{|c|}{ Number of children in the family } \\
\hline$\leq 2$ & $185(92.0)$ & $16(8.0)$ & 1.0 \\
\hline $3-5$ & $195(96.5)$ & $7(3.5)$ & $0.7(0.4-1.2)$ \\
\hline$>5$ & $43(100.0)$ & $0(0.0)$ & $0.3(0.1-1.1)$ \\
\hline
\end{tabular}

$\S=\mathrm{p}$-value $<0.05$.

$\mathrm{COR}=$ Crude Odds Ratio

$\mathrm{Cl}=$ Confidence Interval.

living in urban areas of Dar es Salaam were more than 5 times more likely to be obese compared to their counterparts living in rural settings $(\mathrm{p}=0.002)$.

\section{Socio-demographic factors associated with childhood obesity}

Tables 4 and 5 present results for univariate and multivariate analyses between various independent factors associated with childhood obesity. Children aged above 10 years were 3 times likely to be obese $(\mathrm{COR}=2.9 ; 95 \%$ CI: 1.4-5.9). Girls had twice the risk of being obese compared to boys $(\mathrm{COR}=2.2$; 95\% CI: 1.2-3.7). Urban residence was associated with a three-fold increase in the risk of being obese $(\mathrm{COR}=2.9,95 \% \mathrm{CI}$ : $1.6-5.3)$ and having money to spend at school also doubled the risk of being obese $(\mathrm{COR}=2.2$, 95\% CI: $1.3-3.8)$. 
Table 5 Multivariate logistic regression models for independent predictors of obesity among primary school children in Dar es Salaam, Tanzania 2011

\begin{tabular}{|c|c|c|c|}
\hline Independent variables & Non-obese children N (\%) & Obese children $\mathrm{N}(\%)$ & AOR $(95 \% \mathrm{Cl})$ \\
\hline \multicolumn{4}{|l|}{ Age (Yrs) } \\
\hline 10 years or less & $136(98.5)$ & $2(1.5)$ & 1.0 \\
\hline More than 10 years & $287(93.2)$ & $21(6.8)$ & $3.3(1.5-7.2)^{\S}$ \\
\hline \multicolumn{4}{|l|}{ Gender } \\
\hline Boys & $201(96.2)$ & $8(3.8)$ & 1.0 \\
\hline Girls & $222(93.7)$ & $15(6.3)$ & $2.6(1.4-4.9)^{5}$ \\
\hline \multicolumn{4}{|l|}{ Area of residence } \\
\hline Rural & $194(98.5)$ & $3(1.5)$ & 1.0 \\
\hline Urban & $229(92.0)$ & $20(8.0)$ & $2.5(1.2-5.3)^{\S}$ \\
\hline \multicolumn{4}{|l|}{ Education level of mother } \\
\hline No formal & $26(96.3)$ & $1(3.7)$ & $1.9(0.5-7.2)$ \\
\hline Primary & $139(96.5)$ & $5(3.5)$ & $0.5(0.2-1.4)$ \\
\hline Secondary & 99 (93.4) & $7(6.6)$ & $0.9(0.4-2.3)$ \\
\hline College/University & $63(92.6)$ & $5(7.4)$ & 1.0 \\
\hline Declined response & $82(94.3)$ & $5(5.7)$ & $0.6(0.2-1.8)$ \\
\hline \multicolumn{4}{|l|}{ Occupation of mother } \\
\hline Housewife & $78(90.7)$ & $8(9.3)$ & $1.0(0.3-3.0)$ \\
\hline Business & $176(96.2)$ & $7(3.8)$ & $0.7(0.3-2.1)$ \\
\hline Farmer & $58(98.3)$ & $1(1.7)$ & $0.9(0.3-3.3)$ \\
\hline Government employee & $36(92.3)$ & $3(7.7)$ & 1.0 \\
\hline Other & $56(94.9)$ & $3(5.1)$ & $0.6(0.2-2.1)$ \\
\hline \multicolumn{4}{|l|}{ Money spent at school/day } \\
\hline$\leq 500$ Tshs & $306(97.1)$ & $9(2.9)$ & 1.0 \\
\hline$>500$ Tshs & $117(89.3)$ & $14(10.7)$ & $2.6(1.4-4.8)^{\S}$ \\
\hline \multicolumn{4}{|l|}{ Religion } \\
\hline Christian & $211(93.8)$ & $14(6.2)$ & 1.0 \\
\hline Muslim & $212(95.9)$ & $9(4.1)$ & $1.2(0.6-2.2)$ \\
\hline \multicolumn{4}{|c|}{ Number of adults in the family } \\
\hline$\leq 4$ & $79(91.7)$ & $7(8.3)$ & 1.0 \\
\hline 5 to 7 & $249(94.3)$ & $15(5.7)$ & $0.9(0.4-1.9)$ \\
\hline$>7$ & $95(99.0)$ & $1(1.0)$ & $0.9(0.4-2.5)$ \\
\hline \multicolumn{4}{|c|}{ Number of children in the family } \\
\hline$\leq 2$ & $185(92.0)$ & $16(8.0)$ & 1.0 \\
\hline $3-5$ & $195(96.5)$ & $7(3.5)$ & $0.5(0.3-1.0)$ \\
\hline$>5$ & $43(100.0)$ & $0(0.0)$ & $0.3(0.1-1.1)$ \\
\hline
\end{tabular}

$\S=$ P-value $<0.05$.

$\mathrm{Cl}=$ Confidence Interval.

$\mathrm{AOR}=$ Adjusted Odds Ratio.

After adjusting for all independent variables, age above 10 years $(\mathrm{AOR}=3.3,95 \% \mathrm{CI}=1.5-7.2)$, female sex (AOR=2.6, 95\% $\mathrm{CI}=1.4-4.9)$, urban residence $(\mathrm{AOR}=2.5$, $95 \% \mathrm{CI}=1.2-5.3)$ and having money to spend at school (AOR=2.6, 95\% CI=1.4-4.8) were significant independent determinants of obesity in this population of primary school children.

\section{Discussion}

This study has established the prevalence and determinants of obesity in a representative sample of primary school children in a large business capital of Dar es Salaam. Our results showed that the prevalence of obesity was low (5.2\%). After adjusting for other independent variables, age above 10 years, female gender, urban residence and having 
money to spend at school were the most significant independent determinants of obesity in this population of primary school children.

The prevalence of child obesity found in this study was comparable to that found in previous studies conducted in Tanzania [4,5], and slightly higher compared to that reported from South Africa [26]. Higher prevalence of child obesity has been reported from North Africa [27], and other developing [28,29] and developed countries [30-33]. In this study, prevalence of child obesity was higher among girls than boys. Other studies conducted among children in Africa $[26,27,34]$ and outside Africa [35] have reported similar gender difference in the prevalence of child obesity.

Findings on the association between socioeconomic status with childhood obesity have been controversial, with some studies reporting a positive association of lower education and lower socio-economic status with obesity $[9,36]$. Other studies have demonstrated that family's higher socioeconomic status, increased parental education and high household income to be associated with increased risk of childhood obesity [27,37]. People in the higher socioeconomic strata in the population were the most affected when obesity emerged in developing countries [38]. Our findings have indicated that higher socioeconomic status as shown by higher amount of money given to a child to spend at school per day was associated with increased risk of obesity. Giving child money to spend at school increases the chance of the child to buy fast foods like French fries and sweetened snack like biscuits while at school and consequently, they are predisposed to higher risk of child obesity. Frequent snacking has been reported to be associated with BMI and BMI changes [39].

Our study did not find significant relationship between level of education and occupation of the mother with risk of obesity in children. Our findings appear to differ from conclusions reached by other studies which reported increased risk of overweight among children of mothers with higher education [34]. Contrary to findings from Ghana which documented an association between maternal employment and childhood overweight among advantaged households [40], an Indian study reported maternal unemployment to be a risk factor for childhood overweight [41]. We also had data on religion, number of children and adults in a family, and none of these variables was significantly related to child obesity.

Another interesting finding from our present study was that obese children had significantly higher systolic and diastolic blood pressure. Other studies have also reported similar findings of association between obesity and increased risk of hypertension [42,43]. Although our study did not assess the association between obesity with other health outcomes, there is an increasing body of literature showing that childhood obesity is associated with many other adverse health effects including hyperlipidemia, respiratory disorders, glucose intolerance and type 2 diabetes mellitus, depression and low self-esteem $[15,16,19]$.

Our study has several limitations. The study did not assess many other factors that influence the risk of childhood obesity. Weight gain during pregnancy, maternal obesity and birth weight have been shown to be strongly associated with childhood obesity $[8,22,29]$. Unhealthy dietary pattern and physical inactivity are important factors impacting on the risk of obesity in children $[37,44,45]$. Our study did not gather data to assess the relationship of these variables with the risk of childhood obesity. It is also possible that other unidentified confounders such as genetic factors may have influenced the findings of our study.

\section{Conclusions}

In conclusion, the findings of this study have shaded light on the prevalence and determinants of obesity among primary school children in Tanzania. The prevalence of obesity in this population was found to be low. However, children from urban schools and girls had proportionately higher rates of obesity compared to their counterparts. We recommend further studies to increase our understanding of the prenatal, perinatal and postnatal predictors of childhood obesity. Because early interventions on modifiable risk factors are likely to decrease the rate of childhood obesity, educational programs about obesity and associated health consequences should start early in childhood so as prevent the increasing prevalence of childhood obesity in Tanzania.

\section{Competing interests}

The authors declare that they have no competing interests.

\section{Authors' contributions}

AJM analyzed and interpreted the data, drafted and revised the manuscript. RNM analyzed data and critically reviewed the manuscript. MAN conceived and designed the study, participated in data collection and critically reviewed the manuscript. AA OC SK MM and DN participated in data collection and reviewed the manuscript. BL took anthropometric measurements and reviewed the manuscript. All authors read and approved the final manuscript version.

\section{Acknowledgements}

The authors are very grateful to the parents who consented for their children to participate in this study.

\section{Author details}

${ }^{1}$ Africa Academy for Public Health, Dar es Salaam, Tanzania. ${ }^{2}$ Ifakara Health Institute, Ifakara, Morogoro, Tanzania. ${ }^{3}$ Department of Epidemiology and Biostatistics, Muhimbili University of Health and Allied Sciences, Dar es Salaam, Tanzania. ${ }^{4}$ Department of Physiology, Muhimbili University of Health and Allied Sciences, Dar es Salaam, Tanzania. ${ }^{5}$ Muhimbili National Hospital, Dar es Salaam, Tanzania. ${ }^{6}$ Department of Development Studies, Muhimbili University of Health and Allied Sciences, Dar es Salaam, Tanzania.

${ }^{7}$ Department of Pediatrics and Child Health, Muhimbili University of Health and Allied Sciences, Dar es Salaam, Tanzania. 
Received: 17 June 2013 Accepted: 2 October 2013

Published: 7 October 2013

\section{References}

1. De Onis M, Blössner M, Borghi E: Global prevalence and trends of overweight and obesity among preschool children. Am J Clin Nutr 2010, 92:1257-1264

2. Wang $\mathrm{Y}$, Lobstein $\mathrm{T}$ : Worldwide trends in childhood overweight and obesity. Int J Pediatr Obes 2006, 1:11-25.

3. De Onis M, Blössner M: Prevalence and trends of overweight among preschool children in developing countries. Am J Clin Nutr 2000, 72:1032-1039.

4. Chillo P, Lwakatare J, Janabi M, Matuja W, Greve G: Low prevalence of cardiovascular disease risk factors among primary school children in Tanzania: an opportunity for primordial prevention? Tanzania Medical Journal 2009, 24:9-14.

5. Mosha TCE, Fungo S: Prevalence of overweight and obesity among children aged 6-12 years in Dodoma and Kinondoni municipalities, Tanzania. Tanzan J Health Res 2010, 12:6-16.

6. Kafyulilo AC, Mafumiko FM: Prevalence of overweight and obesity among primary school children in Tanzania: Experiences from Kinondoni and Njombe Districts. Retrieved from http://papers.ssrn.com/sol3/papers.cfm?abstract_id=1630534.

7. Tounian P: Body weight regulation in children: a key to obesity physiopathology understanding. Arch Pediatr 2004, 11:240-244.

8. Knerr I, Topf HG, Hablawetz B, Stöhr W, Dötsch J, Rascher W, Lederer P: Early factors influencing body weight and prevalence of overweight in 4610 children prior to school entry in the Erlangen District (Northern Bavaria). Gesundheitswesen Bundesverband Der Arzte Des Offentlichen Gesundheitsdienstes Germany 2005, 67:183-188.

9. Mei Z, Scanlon KS, Grummer-Strawn LM, Freedman DS, Yip R, Trowbridge $F L$ : Increasing prevalence of overweight among US low-income preschool children: the Centers for Disease Control and Prevention pediatric nutrition surveillance, 1983 to 1995. Pediatrics 1998, 101:E12.

10. Popkin BM, Horton S, Kim S, Mahal A, Shuigao J: Trends in diet, nutritional status, and diet-related non-communicable diseases in China and India: the economic costs of the nutrition transition. Nutr Rev 2001, 59:379-390

11. Maletnlema T: A Tanzanian perspective on the nutrition transition and its implications for health. Public Health Nutr 2002, 5:163-168.

12. Kuga S, Njelekela M, Noguchi T, Kanda T, Yamori T, Mtabaji J: Prevalence of overweight and hypertension in Tanzania: special emphasis on resting energy expenditure and leptin. J Clin Exp Pharmacol Physiol 2002, 26:S23-S26.

13. Arluk SL, Branch JD, Swain DP, Dowling EA: Childhood obesity's relationship to time spent in sedentary behavior. Mil Med 2003, 168:583-586.

14. Cooper AR, Page AS, Foster LJ, Qahwaji D: Commuting to school: are children who walk more physically active? Am J Prev Med 2003, 25:273-276.

15. Freedman DS, Dietz WH, Srinivasan SR, Berenson GS: The relation of overweight to cardiovascular risk factors among children and adolescents: the Bogalusa Heart Study. Pediatrics 1999, 103:1175-1182.

16. Cortese S, Cuzzolaro M, Maffeis C, Piccolo F, Ferrucci G, Tatò L, Pajno-Ferrara F, Dalla Bernardina B: Depressive symptoms and low self-esteem in obese children and adolescents. Minerva Pediatr 2005, 57:65-71.

17. Strauss RS: Childhood obesity and self-esteem. Pediatrics 2000, 105:e15

18. Sinha R, Fisch G, Teague B, Tamborlane WV, Banyas B, Allen K, Savoye M, Rieger V, Taksali S, Barbetta G, Sherwin RS, Caprio S: Prevalence of impaired glucose tolerance among children and adolescents with marked obesity. N Engl J Med 2002, 346:802-810.

19. Viner RM, Segal TY, Lichtarowicz-Krynska E, Hindmarsh P: Prevalence of the insulin resistance syndrome in obesity. Arch Dis Child 2005, 90:10-14.

20. Field AE, Cook NR, Gillman MW: Weight status in childhood as a predictor of becoming overweight or hypertensive in early adulthood. Obes Res 2005, 13:163-169.

21. Garn SM, LaVelle M: Two-decade follow-up of fatness in early childhood. Am J Dis Child 1985, 139:181-185.

22. Rooney BL, Mathiason MA, Schauberger CW: Predictors of obesity in childhood, adolescence, and adulthood in a birth cohort. Matern Child Health J 2011, 15:1166-1175.

23. Epstein LH, Goldfield GS: Physical activity in the treatment of childhood overweight and obesity: current evidence and research issues. Med Sci Sports Exerc 1999, 31:S553-S559.

24. Cogill B: Anthropometric Indicators Measurement Guide. Washington, DC: Food and Nutrition Technical Assistance (FANTA) Project, FHI 360; 2003.
25. Cole T, Bellizzi M, Flegal K, Dietz W: Establishing a standard definition for child overweight and obesity worldwide: international survey. BMJ Clinical Research Ed 2000, 320:1-6.

26. Armstrong MEG, Lambert MI, Sharwood KA, Lambert EV: Obesity and overweight in South African primary school children - the Health of the Nation Study. S Afr Med J SuidAfrikaanse Tydskrif vir Geneeskunde 2006 96:439-444.

27. Taleb S, Agli A: Obesity of the child: Role of the socio-economic factors, parental obesity, food behavior and physical activity in schoolchildren in a city of east Algeria. Cahiers de Nutrition et de Dietetique 2009, 44:198-206.

28. Sharma A, Sharma K, Mathur KP: Growth pattern and prevalence of obesity in affluent schoolchildren of Delhi. Public Health Nutr 2007, 10:485-491.

29. Del Río-Navarro BE, Velázquez-Monroy O, Sánchez-Castillo CP, Lara-Esqueda A, Berber A, Fanghänel G, Violante R, Tapia-Conyer R, James WPT: The high prevalence of overweight and obesity in Mexican children. Obes Res 2004, 12:215-223.

30. Hedley AA, Ogden $C L$, Johnson $C L$, Carroll MD, Curtin LR, Flegal KM: Prevalence of overweight and obesity among US children, adolescents, and adults, 1999-2002. J Am Med Assoc 2004, 291:2847-2850.

31. Lobstein T, Frelut ML: Prevalence of overweight among children in Europe. Obes Rev 2003, 4:195-200.

32. Tremblay MS, Willms JD: Secular trends in the body mass index of Canadian children. CMAJ Can Med Assoc J 2000, 163:1429-1433.

33. World Health Organization: Obesity: Preventing and managing the global epidemic. Report of a WHO consultation. World Health Organ Techn Rep Ser 2000, 894:1-253.

34. Martorell R, Kettel Khan L, Hughes ML, Grummer-Strawn LM: Overweight and obesity in preschool children from developing countries. Int I Obes Related Metabolic Disorders Journal of the International Association for the Study of Obesity 2000, 24:959-967.

35. Wang $Y$, Monteiro C, Barry M: Trends of obesity and underweight in older children and adolescents in the United States, Brazil, China and Russia. Am J Clin Nutr 2002, 75:971-977.

36. Dandona R, Dandona L: Socioeconomic status and obesity. Br J Ophthalmol 2001, 85:1484-1488.

37. Meriem S, Sid MA, Michel N: Predictive factors of obesity and their relationships to dietary intake in schoolchildren in western Algeria. J Clin Med 2011, 6:90-99.

38. Caballero B: The global epidemic of obesity: an overview. Epidemiol Rev 2007, 29:1-5.

39. Hyun HL, Hyun AP, Jae HK, Young GC, Jin KP, Ran L, Ji YY, Ok HK: Factors related to body mass index and body mass index change in Korean children: preliminary results from the obesity and metabolic disorders cohort in childhood. Korean J Fam Med 2012, 33:134-143.

40. Armar-Klemesu M, Ruel MT, Maxwell DG, Levin CE, Morris SS: Poor maternal schooling is the main constraint to good child care practices in Accra. J Nutr 2000, 130:1597-1607.

41. Charaborty P, Anderson AK: Predictors of overweight in children under 5 years of age in India. Curr Res J Soc Sci 2010, 2:138-146.

42. Torrance B, McGuire KA, Lewanczuk R, McGavock J: Overweight, physical activity and high blood pressure in children: a review of the literature. Vasc Health Risk Manag 2007, 3:139-149.

43. Sorof J, Daniels S: Obesity hypertension in children: a problem of epidemic proportions. Hypertension 2002, 40:441-447.

44. Moreno LA, Sarría A, Lázaro A, Bueno M: Dietary fat intake and body mass index in Spanish children. Am J Clin Nutr 2000, 72:1399S-1403S.

45. Tucker $L A$, Seljaas GT, Hager RL: Body fat percentage of children varies according to their diet composition. J Am Diet Assoc 1997, 97:981-986.

doi:10.1186/0778-7367-71-26

Cite this article as: Muhihi et al.: Prevalence and determinants of obesity among primary school children in Dar es Salaam, Tanzania. Archives of Public Health 2013 71:26. 